\title{
Potential constants of borane carbonyl $\left.\right|^{\text {a) }}$
}

\author{
Llewellyn $\mathrm{H}$. Jones \\ Los Alamos Scientific Laboratory, University of California, Los Alamos, New Mexico 87545 \\ Robert C. Taylor \\ Department of Chemistry, University of Michigan, Ann Arbor, Michigan 48106
}

Robert T. Paine

Los Alamos Scientific Laboratory, University of California, Los Alamos, New Mexico 87545 (Received 22 August 1978)

The vibrational spectra of several isotopic species of $\mathrm{BH}_{3} \mathrm{CO}$ in neon matrices at $10^{\circ} \mathrm{K}$ have been observed. A number of combination bands have also been observed, leading to an assignment of most of the fundamental harmonic frequencies of these isotopic species. A least squares normal coordinate treatment, without constraints, has estimated a set of potential constants. We can conclude that the CO bond in $\mathrm{BH}_{3} \mathrm{CO}$ is slightly stronger than that of free $\mathrm{CO}$. The interaction coordinates suggest that unimolecular dissociation of the $\mathrm{B}-\mathrm{C}$ bond proceeds initially toward $\mathrm{BH}_{3}^{-}+\mathrm{CO}^{+}$but reverts to $\mathrm{BH}_{3}+\mathrm{CO}$ before dissociation.

\section{INTRODUCTION}

In discussing the bonding of metal carbonyls, one is often concerned with the effect which bonding to the metal has on the $\mathrm{CO}$ group. We know that $\pi$ bonding of the metal $d$ electrons to the antibonding pi orbitals of the $\mathrm{CO}$ groups weakens the $\mathrm{CO}$ bonds. At the same time it is believed that sigma bonding alone would strengthen the $\mathrm{CO}$ bond as the lone pair of electrons on the carbon, which are used in sigma bond formation, are slightly antibonding ${ }^{1}$ in free CO. Thus, it is of interest to find an example of a carbonyl which forms a single $\mathrm{M}-\mathrm{C}$ sigma bond free of back pi bonding to evaluate the effect of sigma bonding. Borane carbonyl appears to be the best example of such a molecule, though there is the possibility of hyperconjugation ${ }^{2}$ which may put some $\mathrm{H}$ electron density into the $\mathrm{CO}$ antibonding $\pi$ orbitals. Previous estimates of the force field of borane carbonyl have appeared ${ }^{3-5}$ with rather different results, particularly for the $\mathrm{CO}$ bond strength. The first of these ${ }^{3}$ was from the infrared spectrum of the gas phase using frequencies for some isotopically enriched species $\left({ }^{10} B, D\right)$. Unfortunately the gas phase absorption bands are rather asymmetric and not suitable for locating the band center under the available resolution. Another report, ${ }^{4}$ which appeared at about the same time, was based on Raman spectra of the liquid for which the bands are rather broad. In neither case were ${ }^{13} \mathrm{C}$ or ${ }^{18} \mathrm{O}$ isotope shifts available so a number of constraints were introduced to derive the potential function.

In this work we have prepared a number of isotopically enriched borane carbonyls and have observed most of the fundamental frequencies of ten isotopic species. The spectra were recorded in a low temperature, rare gas matrix so that sharp peaks could be attained and accurate isotope shifts determined.

\footnotetext{
a) This work performed under the auspices of the U. S. Department of Energy.
}

\section{EXPERIMENTAL SECTION}

Standard high vacuum gas handling techniques were used for the manipulation of the volatile compounds. The purities of the starting materials, diborane and carbon monoxide, were verified by mass and infrared spectra of gaseous samples. The ${ }^{n} \mathrm{~B}_{2} \mathrm{H}_{6}$ was obtained from the reduction of $\mathrm{BF}_{3} \cdot \mathrm{O}\left(\mathrm{C}_{2} \mathrm{H}_{5}\right)_{2}$ by $\mathrm{LiAlH}_{4 \cdot}{ }^{6}$ Boron10 enriched diborane was obtained in a similar fashion from ${ }^{10} \mathrm{BF}_{3} \cdot \mathrm{O}\left(\mathrm{C}_{2} \mathrm{H}_{5}\right)_{2}$ which was generated thermally from $\mathrm{CaF}_{2}{ }^{10} \mathrm{BF}_{3}$ complex (Oak Ridge National Laboratory). The ${ }^{n} \mathrm{~B}_{2} \mathrm{D}_{6}$ was obtained from the action of $\mathrm{NaBD}_{4}$ (Alpha) on polyphosphoric acid. The diborane was subjected to triple vacuum trap to trap distillation prior to use. The carbon monoxide ${ }^{13} \mathrm{CO}\left(94 \%{ }^{13} \mathrm{C}\right)$ was obtained from Los Alamos Scientific Laboratory and the ${ }^{12} \mathrm{C}^{18} \mathrm{O}$ sample was obtained from Bio Rad Laboratories.

The borane carbonyl samples of varying isotopic constitution were all prepared in the same fashion using the technique described by Carter. ${ }^{7}$ Typically, a $10 \mathrm{mmol}$ sample of diborane was condensed into a $25 \mathrm{ml}$ high pressure, stainless steel bomb fitted with a high pressure valve and gauge. The carbon monoxide was then condensed onto the diborane in a five - to tenfold excess. The bomb was closed and allowed to warm to room temperature. After twelve hours the volatile products were fractionated through traps cooled to $-96^{\circ},-160^{\circ}$, and $-196^{\circ} \mathrm{C}$. The borane carbonyls were retained at $-160^{\circ}$ and stored at $-196^{\circ} \mathrm{C}$.

For all the low temperature matrices a Displex model 202S closed cycle refrigerator with CsI windows was used. The $\mathrm{BH}_{3} \mathrm{CO}$ was mixed with neon or argon at a ratio of in in a liter bulb kept at dry ice temperature to inhibit decomposition. The mixture was deposited slowly (several min. per Torr 1) through a metering valve onto a cold CsI window. The spectra were observed in transmission. Such matrices prepared with argon exhibited splitting of the degenerate fundamentals suggesting significant distortion of the $\mathrm{BH}_{3} \mathrm{CO}$ molecule in the matrix. However, the size of the $\mathrm{BH}_{3} \mathrm{CO}$ mole- 
TABLE I. Observed vibrational frequencies (in $\mathrm{cm}^{-1}$ ) for various isotopic species, ${ }^{i} H_{3}^{j} B^{k} C^{l} O$, in neon matrices at $10^{\circ} \mathrm{K}$.

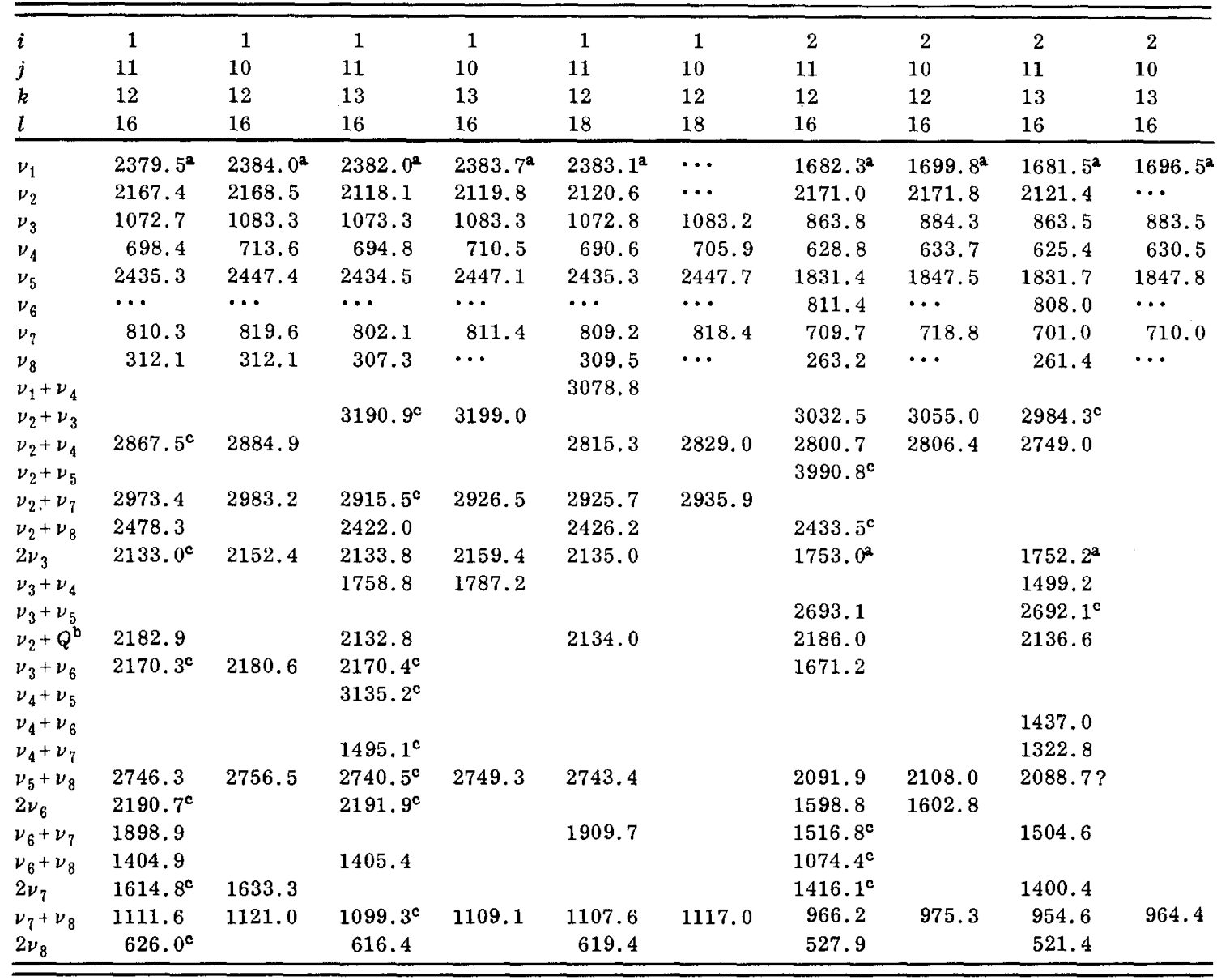

a Observed in Raman spectrum of neon matrix.

${ }^{b} Q$ is a transition whose origin is not yet clear (see text).

Overtone or combination band used in establishing anharmonicity.

cule with $C_{3 v}$ symmetry is about right to fit into a neon matrix in place of four neon atoms in a tetrahedral array, with the $\mathrm{CO}$ group aligned along a $C_{3}$ axis. Therefore, we deposited $\mathrm{BH}_{3} \mathrm{CO}$ in a neon matrix at about $9^{\circ} \mathrm{K}$ and were pleased to find that the degenerate modes were not split though the $\mathrm{BCO}$ bending mode is somewhat broader than the other fundamentals. This indicates that the $\mathrm{BH}_{3} \mathrm{CO}$ is not significantly distorted from $C_{3 v}$ symmetry in a neon matrix. We consequently studied all the isotopic species $\left(\mathrm{BH}_{3} \mathrm{CO}, \mathrm{BD}_{3} \mathrm{CO}, \mathrm{BH}_{3}{ }^{13} \mathrm{CO}, \mathrm{BH}_{3} \mathrm{C}^{18} \mathrm{O}\right.$, and $\mathrm{BD}_{3}{ }^{13} \mathrm{CO}$ ) in neon matrices. The natural abundance of boron $\left(80 \%{ }^{11} \mathrm{~B}, 20 \%{ }^{10} \mathrm{~B}\right)$ was satisfactory for assigning most of the ${ }^{10} \mathrm{~B}$ and ${ }^{11} \mathrm{~B}$ fundamentals. Some uncer tainties were clarified by studying $\mathrm{BH}_{3} \mathrm{CO}$ with $\sim 50 \%$ ${ }^{10} \mathrm{~B}$ and $50 \%{ }^{11} \mathrm{~B}$.

The spectra were observed on a Perkin-Elmer 180 spectrometer. Raman spectra were also studied primarily to observe the symmetric $B-H$ stretch which is very weak in the infrared, Rather thick deposits on a copper block at $10^{\circ} \mathrm{K}$ were required for the Raman study. We used a mixture $\mathrm{Ne} / \mathrm{BH}_{3} \mathrm{CO}=\frac{200}{1}$ and deposited about 100 Torr 1 over about $5 \mathrm{~cm}^{2}$ of the block.

\section{Spectral observations and frequency assignments}

As discussed later, $\mathrm{BH}_{3} \mathrm{CO}$ has $C_{3 v}$ symmetry and thus has four $A_{1}$ type frequencies and $4 E$ type frequencies. We have observed most of the fundamentals for ten isotopic species together with a number of combination bands. Table I lists the frequencies observed in neon matrices and Table II the frequencies of solid films. Parts of the spectrum of the normal species are shown in Fig. 1. We hoped to observe enough combination bands to determine the various anharmonicity corrections, $X_{i j}$, in the energy level expression

$$
G_{v_{1}, v_{2}}=\Sigma \omega_{i}\left(v_{i}+d_{i} / 2\right)+\sum_{i \leqslant j} X_{i j}\left(v_{i}+d_{i} / 2\right)\left(v_{j}+d_{j} / 2\right)
$$

However, in the neon matrix relatively few combinations and overtones were observable. In order to supplement these data we also observed spectra of the pure solids at $10^{\circ} \mathrm{K}$. Most of these data are listed in Table III. Though the anharmonicity corrections are not necessarily the same in matrix and pure solid, such an assumption should be a reasonable approximation and was used.

The earlier work ${ }^{3,4}$ has been of great help in assign- 
TABLE I. Infrared absorption frequencies (in $\mathrm{cm}^{-1}$ ) for solid films of ${ }^{i} H_{3}{ }^{j} B^{k} C^{l} O$ at $10^{\circ} \mathrm{K}$.

\begin{tabular}{|c|c|c|c|c|c|c|c|c|c|c|}
\hline$i$ & 1 & 1 & 1 & 1 & 1 & 1 & 2 & 2 & 2 & 2 \\
\hline$j$ & 11 & 10 & 11 & 10 & 11 & 10 & 11 & 10 & 11 & 10 \\
\hline$k$ & 12 & 12 & 13 & 13 & 12 & 12 & 12 & 12 & 13 & 13 \\
\hline$l$ & 16 & 16 & 16 & 16 & 18 & 18 & 16 & 16 & 16 & 16 \\
\hline$\nu_{1}$ & 2377.7 & 2382.0 & 2375.6 & 2381.2 & 2379.0 & $\cdots$ & 1687.1 & 1698.0 & $\cdots$ & $\cdots$ \\
\hline$\nu_{2}$ & 2185.1 & $\cdots$ & 2134.8 & 2136.5 & 2123.4 & $\cdots$ & 2187.9 & $\cdots$ & 2138.6 & $\cdots$ \\
\hline$\nu_{3}$ & 1078.1 & 1089.2 & 1077.8 & 1088.7 & 1077.5 & 1091.5 & 868.0 & $\cdots$ & 868.5 & 889.0 \\
\hline$\nu_{4}$ & 693.1 & 707.9 & 688.7 & 703.7 & 686.0 & 697.0 & 622.7 & ... & 620.0 & $\cdots$ \\
\hline 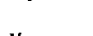 & $\{2425.7$ & 2436.0 & 2423.0 & $\cdots$ & 2426.0 & $\cdots$ & 1824.0 & 1839.0 & 1842.2 & $\cdots$ \\
\hline$\nu_{5}$ & $\{2440.5$ & 2451.0 & 2436.0 & ... & 2437.0 & $\cdots$ & 1833.7 & 1850.0 & 1834.9 & $\cdots$ \\
\hline$\nu_{6}$ & $\left\{\begin{array}{l}1105.8 \\
1112.2\end{array}\right.$ & $\cdots$ & 1106.3 & $\cdots$ & 1107.5 & $\cdots$ & 814.1 & $\cdots$ & 810.9 & 812.2 \\
\hline$\nu_{\eta}$ & $\{817.3$ & 826.7 & 809.4 & 818.6 & 816.0 & 825.0 & 710.6 & 720.4 & 701.5 & 711.5 \\
\hline 7 & ( 822.3 & 831.0 & 809.4 & 822.8 & 821.0 & 830.0 & 713.4 & 722.2 & 703.5 & 713.5 \\
\hline$\nu_{8}$ & 314.5 & $\cdots$ & 308.1 & $\cdots$ & $\cdots$ & $\cdots$ & 274.5 & $\cdots$ & $\cdots$ & $\cdots$ \\
\hline $2 \nu_{1}$ & $4734.3^{2}$ & & $4730.7^{2}$ & & & & & & & \\
\hline$\nu_{1}+\nu_{2}$ & $4556.9^{2}$ & 4562.3 & 4507.4 & 4511.2 & & & & & & \\
\hline$\nu_{1}+\nu_{4}$ & & & & & & & 2313.0 & & & \\
\hline$\nu_{1}+\nu_{5}$ & $4751.2^{2}$ & 4764.8 & $4751.9^{a}$ & 4766.8 & & & & & & \\
\hline$\nu_{1}+\nu_{7}$ & $3194.0^{\mathrm{a}}$ & 3207.4 & & & & & & & & \\
\hline$\nu_{1}+\nu_{8}$ & 2699.0 & & & & & & & & & \\
\hline $2 \nu_{2}$ & $4344.4^{2}$ & & $4246.0^{\mathrm{a}}$ & & & & & & & \\
\hline$\nu_{2}+\nu_{4}$ & 2875.2 & 2888.9 & & & & & & & & \\
\hline$\nu_{2}+\nu_{5}$ & $\left\{\begin{array}{l}4602.0 \\
46173\end{array}\right.$ & 4629.9 & 4552.7 & 4563.0 & & & & & & \\
\hline$\nu_{2}+\nu_{6}$ & 14617.0 & & & & & & $3004.3^{a}$ & & & \\
\hline $2 v_{3}$ & & & & 2143.7 & 2162.6 & & & & & \\
\hline$\nu_{3}+\nu_{4}$ & $1761.6^{2}$ & 1785.6 & & & & . & & & & \\
\hline$\nu_{3}+\nu_{5}$ & $3505.0 ?$ & & & & & & & & & \\
\hline$\nu_{3}+\nu_{6}$ & & & 2174.7 & & & & 1679.0 & & & \\
\hline$\nu_{3}+\nu_{7}$ & $1890.8^{\mathrm{a}}$ & 1906.7 & & & & & & & & \\
\hline$\nu_{3}+\nu_{8}$ & $1391.7^{2}$ & & & & & & & & & \\
\hline $2 \nu_{4}$ & $1373.7^{2}$ & 1401.7 & & & & & & & & \\
\hline$\nu_{4}+\nu_{5}$ & $\{3121.0$ & & & & & & & & & \\
\hline$\nu_{4}+\nu_{6}$ & & 18224 & & & & & & & & \\
\hline$\nu_{4}+\nu_{7}$ & 1509.0 & 1533.2 & & & & & & & & \\
\hline $2 \nu_{5}$ & $4816.0^{2}$ & & 4816.0 & 4834.4 & & & & & & \\
\hline$\nu_{5}+\nu_{6}$ & 3556.0 & & & & & & $\left\{\begin{array}{l}2630.5 \\
2640.6^{2}\end{array}\right.$ & & 2638.4 & \\
\hline$\nu_{5}+\nu_{7}$ & 3255.0 & 3266.3 & & & & & & & & \\
\hline$\nu_{6}+\nu_{8}$ & 1422.6 & 1426.9 & & & & & & & & \\
\hline $2 \nu_{7}$ & $\{1629.4$ & 1648.4 & 1614.4 & & & & & & & \\
\hline$\nu_{7}+\nu_{8}$ & 1128.1 & 1136.7 & 1106.4 & & & & & & & \\
\hline
\end{tabular}

2Overtone or combination used to establish anharmonicity.

ing the fundamental frequencies. We shall discuss them individually.

$\nu_{1}$. This is mainly the symmetrical $\mathrm{BH}$ stretch and is very weak in the infrared so we have relied primarily on the Raman shifts for the assignments. As noted previously, ${ }^{4}$ for $\mathrm{BD}_{3} \mathrm{CO}$ there is a strong Fermi resonance of $\nu_{1}$ with $2 \nu_{3}$. We find this to be true for both ${ }^{11} \mathrm{BD}_{3}{ }^{12} \mathrm{C}^{16} \mathrm{O}$ and ${ }^{11} \mathrm{BD}_{3}{ }^{13} \mathrm{C}^{16} \mathrm{O}$. For the ${ }^{10} \mathrm{~B}$ species resonance is somewhat weaker. As seen in Table I we have observed $\nu_{1}$ and $2 \nu_{3}$ for ${ }^{11} \mathrm{BD}_{3}{ }^{12} \mathrm{C}^{16} \mathrm{O}$ and ${ }^{11} \mathrm{BD}_{3}{ }^{13} \mathrm{C}^{16} \mathrm{O}$ and $\nu_{1}$ for the ${ }^{10} \mathrm{~B}$ species. The Fermi perturbation can be described by the relation ${ }^{8}$

$$
\pm D_{v, v^{\circ}}=\frac{1}{2}\left[\left(\delta^{2}+4 W_{v, v^{\circ}}^{2}\right)^{1 / 2}-\delta\right]
$$

Where $\delta$ is the separation of unperturbed levels, $v$ and $v^{\prime}, W_{v_{t}, v^{\prime}}$ is the Fermi interaction constant $\left(\int \psi_{v}^{0} W \psi_{v^{\prime}} d \tau\right)$, and $\pm D$ is the displacement of the observed levels from their unperturbed positions. If we know the anharmo-

TABLE III. Fermi interaction constant and unperturbed frequencies in $\mathrm{cm}^{-1}$ for $\nu_{1}$ and $2 \nu_{3}$ of $\mathrm{BD}_{3} \mathrm{CO}$.

\begin{tabular}{lcccc}
\hline \hline & ${ }^{11} \mathrm{BD}_{3}{ }^{12} \mathrm{C}^{16} \mathrm{O}$ & ${ }^{11} \mathrm{BD}_{3}{ }^{13} \mathrm{C}^{16} \mathrm{O}$ & ${ }^{10} \mathrm{BD}_{3}{ }^{12} \mathrm{C}^{16} \mathrm{O}$ & ${ }^{10} \mathrm{BD}_{3}{ }^{13} \mathrm{C}^{16} \mathrm{O}$ \\
\hline$W$ & 35.3 & 35.3 & $(35.3)^{2}$ & $(35.3)^{2}$ \\
$\left(\nu_{1}\right)_{0}$ & 1716.1 & 1715.1 & 1718.1 & 1716.7 \\
$\left(2 \nu_{3}\right)_{0}$ & 1719.2 & 1718.6 & 1759.9 & 1758.3 \\
\hline \hline
\end{tabular}

${ }^{2}$ Assumed the same as the ${ }^{11} \mathrm{~B}$ values. 

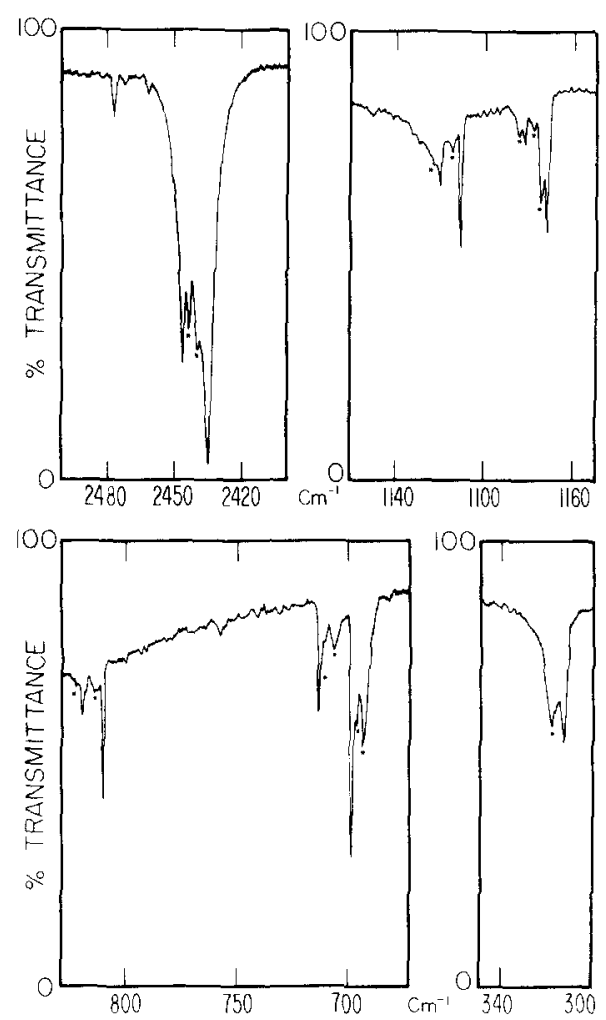

FIG. 1. Neon matrix of $\mathrm{BH}_{3} \mathrm{CO}: 1000 / 110^{\circ} \mathrm{K} \sim 4 \mu$ mole $\mathrm{BH}_{3} \mathrm{CO} / \mathrm{cm}^{2}$. Absorptions labeled with $*$ are believed to arise from aggregates of interacting $\mathrm{BH}_{3} \mathrm{CO}$ molecules.

nicity constant, $X_{33}$, we can calculate the "unperturbed" values for $\left(2 \nu_{3}\right)_{0}$. With this information and the observed values from Table I for $\nu_{1}$ and $2 \nu_{3}$ of the ${ }^{11} \mathrm{BD}_{3} \mathrm{CO}$ species we can calculate $W$ and the unperturbed values of $\left(\nu_{1}\right)_{0}$. Assuming $W$ is the same, we can then calculate the values of $\left(\nu_{1}\right)_{0}$ for the ${ }^{10} \mathrm{~B}$ species. For the $H$ species $X_{33}$ is found to be about $-6.4 \mathrm{~cm}^{-1}$. Using the usual relation $X_{i j}^{k}=\left[\omega_{i}^{k} \omega_{j}^{k} / \omega_{i}^{l} \omega_{j}^{l}\right] X_{i j}^{l}$ we find $X_{33}=-4.2$ for ${ }^{11} \mathrm{BD}_{3} \mathrm{CO}$ and -4.35 for ${ }^{19} \mathrm{BD}_{3} \mathrm{CO}$. We are then able to calculate the results listed in Table III.

$\nu_{2}$. This is primarily the CO stretching mode and gives rise to the strongest band in infrared absorption. There is no problem in assigning the $\nu_{2}$ peaks; however, there are combination bands in this region which complicate the structure somewhat. In Fig. 2 we show this region for the normal species. The major peaks shown here have been assigned except for that at $2183 \mathrm{~cm}^{-1}$. This poses an anomaly as an analogous peak occurs for all ${ }^{11} \mathrm{~B}$ isotopic species at about $15 \mathrm{~cm}^{-1}$ above the $\nu_{2}$ fundamental. There is no combination of internal modes which would fall in such a position for the different isotopic species. We have assigned it as a combination of $\nu_{2}+Q$ where $Q$ is $15 \mathrm{~cm}^{-1}$ for all species. One might speculate that it arises from a combination of $\nu_{2}$ with a phonon mode of the neon lattice or with a translational or librational mode of $\mathrm{BH}_{3} \mathrm{CO}$ in the neon lattice. How ever, in an argon matrix a similar strong band occurs at $\nu_{2}+15$ which tends to rule out the matrix material as contributing to such a band. Another thought was that thi $s$ band may arise from a dimer, or aggregate of sev- eral $\mathrm{BH}_{3} \mathrm{CO}$ molecules, as it comes near the frequency for pure, solid $\mathrm{BH}_{3} \mathrm{CO}$ (see Table II). However, dilution does not affect its relative intensity; thus, at neon/ $\mathrm{BH}_{3} \mathrm{CO}=5000 / 1$ this band at $2183 \mathrm{~cm}^{-1}$ is just as intense relative to $\nu_{2}$ as at a ratio of $1000 / 1$. This seems to rule out aggregates as an explanation; for the present we must consider this band unexplained.

$\nu_{3}$ and $\nu_{4}$. These $A_{1}$ modes are easily assigned by comparison with previous work ${ }^{3,4}$ and the expected isotope shifts.

$\nu_{5}$. This is primarily antisymmetric BH stretch and is readily assigned to the strong absorptions in the 2400 $\mathrm{cm}^{-1}$ region for $\mathrm{BH}$ and $1800 \mathrm{~cm}^{-1}$ for $\mathrm{BD}$.

$\nu_{6}$. The assignment of this mode, which is an antisymmetric $\mathrm{HBH}$ deformation, gave problems. It was originally thought to give rise to some relatively strong peaks slightly over $1100 \mathrm{~cm}^{-1}$ for the $H$ species. This would be in agreement with the assignments of Taylor ${ }^{4}$ from the Raman spectra. However, the relatively large isotope shifts for ${ }^{10} \mathrm{~B} /{ }^{11} \mathrm{~B},{ }^{12} \mathrm{C} /{ }^{13} \mathrm{C}$, and ${ }^{16} \mathrm{O} /{ }^{18} \mathrm{O}$ for this absorption rule out its assignment as $\nu_{6}$; instead, it is more satisfactorily assigned as the combination $\nu_{7}+\nu_{8}$ for which the isotope shift is in close agreement. The fundamental $\nu_{6}$ has been observed for $\mathrm{BD}_{3} \mathrm{CO}$ and $\mathrm{BD}_{3}{ }^{13} \mathrm{CO}$ as a weak band at 811.4 and $808.0 \mathrm{~cm}^{-1}$, respectively. Apparently for the $H$ species $\nu_{6}$ is weaker than $\nu_{7}+\nu_{8}$ and lost in the latter. Its assignment in the $H$ species can be approximated from the pure solid spectra for which $\nu_{7}+\nu_{8}$ is well shifted from the $\nu_{6}$ region. From this observation and the solid-matrix shift for the deuterium species we estimate $\nu_{6} \approx 1105.5 \mathrm{~cm}^{-1}$ for ${ }^{11} \mathrm{BH}_{3} \mathrm{CO}$ in a neon matrix.

$\nu_{7}$ and $\nu_{8}$. There is no problem in the assignment of these two $E$ modes $-\mathrm{BH}_{3}$ rock and $\mathrm{BCO}$ bend, respectively.

We should point out that there are spurious bands near the sharp peaks of $\nu_{7}, \nu_{3}$, and $\nu_{7}+\nu_{8}$. We believe these arise from aggregates since they decrease in intensity with respect to the nearby sharp peaks for more dilute matrices.

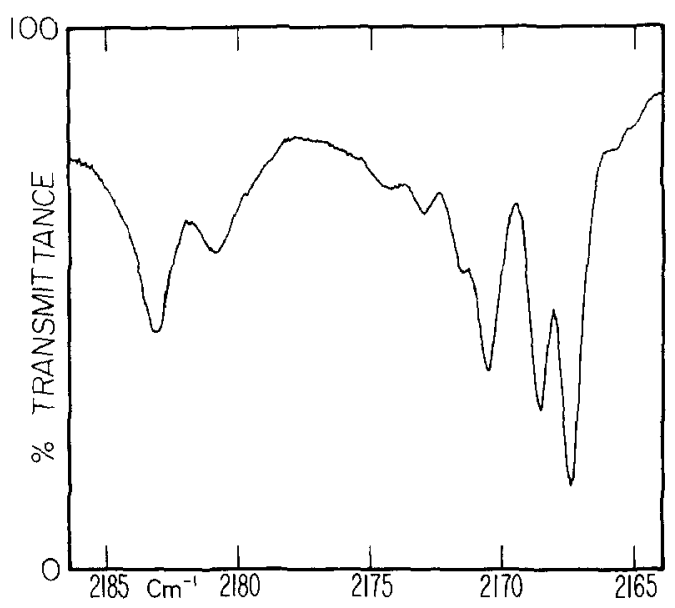

FIG. 2. Neon matrix of $\mathrm{BH}_{3} \mathrm{CO}: 1000 / 110^{\circ} \mathrm{K} \sim 0.8 \mu$ mole $\mathrm{BH}_{3} \mathrm{CO} / \mathrm{cm}^{2}$. 
TABLE IV. Anharmonic corrections for $\mathrm{H}_{3}{ }^{11} \mathrm{~B}^{12} \mathrm{C}^{16} \mathrm{O}$ and harmonic frequencies for ${ }^{i} \mathrm{H}_{3}{ }^{j} \mathrm{~B}^{k} \mathrm{C}^{l} \mathrm{O}$ in $\mathrm{cm}^{-1}$.

\begin{tabular}{|c|c|c|c|c|c|c|c|c|c|c|c|}
\hline $\begin{array}{l}X_{11} \\
X_{12} \\
X_{13} \\
X_{14} \\
X_{15} \\
X_{16} \\
X_{17} \\
X_{18} \\
X_{22} \\
i-j-k-l\end{array}$ & $\begin{array}{r}-10.5 \\
-5.8 \\
0.0 \\
0.0 \\
-60.0 \\
0.0 \\
-6.0 \\
0.0 \\
-12.5 \\
\rightarrow\end{array}$ & $1-10-12-16$ & $\begin{array}{l}X_{23} \\
X_{24} \\
X_{25} \\
X_{26} \\
X_{27} \\
X_{28} \\
X_{33} \\
X_{34} \\
X_{35} \\
1-11-12-16\end{array}$ & $\begin{array}{l}-1.0 \\
+1.7 \\
-15.0 \\
+3.0 \\
-4.7 \\
-3.0 \\
-6.4 \\
-9.0 \\
-5.1 \\
2-10-12-16\end{array}$ & $2-11-12-16$ & $\begin{array}{l}X_{36} \\
X_{37} \\
X_{38} \\
X_{44} \\
X_{45} \\
X_{46} \\
X_{47} \\
X_{48} \\
X_{55} \\
1-10-13-16\end{array}$ & $\begin{array}{l}-8.0 \\
-6.0 \\
-3.0 \\
-6.0 \\
+4.0 \\
+4.8 \\
-1.8 \\
+3.5 \\
-33.0 \\
1-11-13-16\end{array}$ & $2-10-13-16$ & $\begin{array}{l}X_{56} \\
X_{57} \\
X_{58} \\
X_{66} \\
X_{67} \\
X_{68} \\
X_{77} \\
X_{78} \\
X_{88} \\
2-11-13-16\end{array}$ & $\begin{array}{r}-13.0 \\
0.0 \\
-1.3 \\
-10.0 \\
-6.7 \\
0.0 \\
-2.5 \\
-10.0 \\
+1.0 \\
1-10-12-18\end{array}$ & $1-11-12-18$ \\
\hline$\omega_{1}$ & & $\begin{array}{r}2474.5 \\
25.0^{\mathrm{a}}\end{array}$ & $\begin{array}{r}2469.4 \\
25.0\end{array}$ & $\begin{array}{r}1767.9 \\
0.25\end{array}$ & $\begin{array}{r}1765.5 \\
1.0\end{array}$ & $\begin{array}{r}2474.0 \\
0.0\end{array}$ & $\begin{array}{r}2471.9 \\
25.0\end{array}$ & $\begin{array}{r}1766.3 \\
0.25\end{array}$ & $\begin{array}{r}1764.3 \\
1.0\end{array}$ & $\begin{array}{r}2475.0 \\
0.0\end{array}$ & $\begin{array}{r}2473.1 \\
25.0\end{array}$ \\
\hline$\omega_{2}$ & & $\begin{array}{r}2215.9 \\
100.0\end{array}$ & $\begin{array}{r}2214.7 \\
100.0\end{array}$ & $\begin{array}{r}2214.6 \\
100.0\end{array}$ & $\begin{array}{r}2213.6 \\
100.0\end{array}$ & $\begin{array}{r}2165.5 \\
0.0\end{array}$ & $\begin{array}{r}2163.6 \\
100.0\end{array}$ & $\begin{array}{r}2162.3 \\
0.0\end{array}$ & $\begin{array}{r}2162.2 \\
100.0\end{array}$ & $\begin{array}{r}2168.1 \\
1.0\end{array}$ & $\begin{array}{r}2166.3 \\
100.0\end{array}$ \\
\hline$\omega_{3}$ & & $\begin{array}{r}1123.9 \\
25.0\end{array}$ & $\begin{array}{r}1112.6 \\
25.0\end{array}$ & $\begin{array}{r}911.3 \\
1.0\end{array}$ & $\begin{array}{r}889.9 \\
1.0\end{array}$ & $\begin{array}{r}1123.8 \\
25.0\end{array}$ & $\begin{array}{r}1113.1 \\
25.0\end{array}$ & $\begin{array}{r}910.3 \\
1.0\end{array}$ & $\begin{array}{r}889.4 \\
25.0\end{array}$ & $\begin{array}{r}1123.7 \\
0.0\end{array}$ & $\begin{array}{r}1112.7 \\
25.0\end{array}$ \\
\hline$\omega_{4}$ & & $\begin{array}{r}719.2 \\
6.0\end{array}$ & $\begin{array}{r}703.6 \\
6.0\end{array}$ & $\begin{array}{r}639.0 \\
6.0\end{array}$ & $\begin{array}{r}633.9 \\
6.0\end{array}$ & $\begin{array}{r}716.1 \\
6.0\end{array}$ & $\begin{array}{r}699.9 \\
6.0\end{array}$ & $\begin{array}{r}635.7 \\
6.0\end{array}$ & $\begin{array}{r}630.5 \\
6.0\end{array}$ & $\begin{array}{r}711.3 \\
6.0\end{array}$ & $\begin{array}{r}695.6 \\
6.0\end{array}$ \\
\hline$\omega_{6}$ & & $\begin{array}{r}1156.8 \\
0.0\end{array}$ & $\begin{array}{r}1155.3 \\
1.0\end{array}$ & $\begin{array}{r}839.5 \\
0.0\end{array}$ & $\begin{array}{r}838.7 \\
11.0\end{array}$ & $\begin{array}{r}1157.3 \\
0.0\end{array}$ & $\begin{array}{r}1155.9 \\
0.0\end{array}$ & $\begin{array}{r}836.7 \\
0.0\end{array}$ & $\begin{array}{r}835.1 \\
11.0\end{array}$ & $\begin{array}{r}1157.5 \\
0.0\end{array}$ & $\begin{array}{r}1156.0 \\
0.0\end{array}$ \\
\hline$\omega_{7}$ & & $\begin{array}{r}853.6 \\
25.0\end{array}$ & $\begin{array}{r}843.8 \\
25.0\end{array}$ & $\begin{array}{r}743.5 \\
25.0\end{array}$ & $\begin{array}{r}733.9 \\
25.0\end{array}$ & $\begin{array}{r}844.8 \\
25.0\end{array}$ & $\begin{array}{r}834.9 \\
25.0\end{array}$ & $\begin{array}{r}734.2 \\
25.0\end{array}$ & $\begin{array}{r}724.7 \\
25.0\end{array}$ & $\begin{array}{r}852.2 \\
25.0\end{array}$ & $\begin{array}{r}842.5 \\
25.0\end{array}$ \\
\hline$\omega_{8}$ & & $\begin{array}{r}321.8 \\
11.0\end{array}$ & $\begin{array}{r}321.7 \\
11.0\end{array}$ & $\begin{array}{r}270.5 \\
0.0\end{array}$ & $\begin{array}{r}270.2 \\
11.0\end{array}$ & $\begin{array}{r}316.7 \\
0.0\end{array}$ & $\begin{array}{r}316.6 \\
11.0\end{array}$ & $\begin{array}{r}268.4 \\
0.0\end{array}$ & $\begin{array}{r}268.3 \\
11.0\end{array}$ & $\begin{array}{r}319.1 \\
0.0\end{array}$ & $\begin{array}{r}319.0 \\
11.0\end{array}$ \\
\hline
\end{tabular}

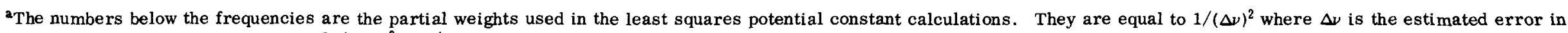
observed frequency. Total weight $=\left[1 /\left(\Delta \nu_{i}\right)^{2}\right] \cdot\left[1 / \lambda_{i}\right]$. 
TABLE V. Symmetry coordinates $\mathrm{s}^{\mathbf{a}, \mathfrak{b}}$ for $\mathrm{BH}_{3} \mathrm{CO}$ of $\mathrm{C}_{3 v}$ symmetry.

$$
\begin{array}{ll}
\hline A_{1} \quad & =\frac{1}{\sqrt{3}}\left(d_{1}+d_{2}+d_{3}\right) \\
S_{2} & =r \\
S_{3} & =\left[b\left(\alpha_{1}+\alpha_{2}+\alpha_{3}\right)-\left(\beta_{1}+\beta_{2}+\beta_{3}\right)\right] /\left[3\left(1+b^{2}\right)\right]^{1 / 2} \\
S_{4} & =R \\
S_{5} & =\frac{1}{\sqrt{6}}\left(2 d_{1}-d_{2}-d_{3}\right) \\
S_{6} & =\frac{1}{\sqrt{6}}\left(2 \alpha_{23}-\alpha_{12}-\alpha_{13}\right) \\
S_{7} & =\frac{1}{\sqrt{6}}\left(2 \beta_{1}-\beta_{2}-\beta_{3}\right) \\
S_{8} & =\gamma
\end{array}
$$

ab is a constant $=-3 \sin \beta_{0} \cos \beta_{0} / \sin \alpha_{0}$

the internal coordinates given are, of course, displacements $\left(d_{1}=\Delta d_{1}\right)$.

From the observation of overtones and combination bands many of the anharmonicity corrections have been estimated. This has made it possible to estimate the harmonic fundamental frequencies from the usual relationship

$$
\omega_{i}=\nu_{i}-X_{i i}\left(1+d_{i}\right)-\sum_{j<i} X_{i j} \frac{d_{j}}{2} .
$$

Unfortunately, for most $X_{1\}}$, experimental data were not

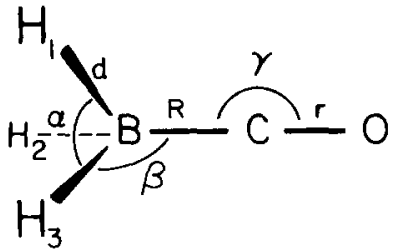

FIG. 3. Internal coordinates of $\mathrm{BH}_{3} \mathrm{CO}$. available for all the isotopic species. Therefore use was made of the standard approximacion $X_{i j}^{k}=X_{i j}^{l} \nu_{i}^{k} \nu_{j}^{k} /$ $\nu_{i}^{l} \nu_{j}^{l}$ to provide the missing values. Two of the anhar monicity corrections were estimated from high resolution work, namely $X_{28}{ }^{9 \mathrm{a}}$ and $X_{48 .}{ }^{9 \mathrm{~b}}$ The ones estimated from our neon matrix studies are $X_{23}, X_{24}, X_{25}, X_{27}$, $X_{33}, X_{35}, X_{36}, X_{38} X_{45}, X_{46}, X_{47}, X_{58}, X_{67}, X_{77}, X_{78}$, and $X_{88}$. Other constants were transferred from observations on the pure solid; namely, $X_{11}, X_{12}, X_{15}, X_{17}, X_{22}$, $X_{26}, X_{34}, X_{37}, X_{44}, X_{55}, X_{56}$, and $X_{66}$. A number of values were assigned as 0.0 as there was no consistent information concerning them; these are $X_{13}, X_{14}, X_{16}, X_{18}$, $X_{57}$, and $X_{68}$.

The estimated anharmonic corrections, $X_{i j}$, for the normal species and harmonic frequencies, $\omega_{i}$, for all

\begin{tabular}{|c|c|c|c|c|c|c|c|}
\hline \multicolumn{6}{|c|}{$A_{1}$} & \multicolumn{2}{|c|}{$E$} \\
\hline & & Harmonic $\nu$ & Observed $v$ & & & Harmonic $\nu$ & Observed $\nu$ \\
\hline$\overline{F_{11}}$ & $\mathrm{BH}$ & $3.50^{\mathrm{a}}(15)^{\mathrm{b}}$ & 3.25 & $\overline{F_{55}}$ & $\mathrm{BH}$ & $3.58(5)$ & 3.10 \\
\hline$F_{22}$ & $\mathrm{CO}$ & $19.24(13)$ & 18.67 & $F_{66}$ & $\alpha$ & $0.365(15)$ & 0.31 \\
\hline$F_{33}$ & $\alpha(\mathrm{HBH})$ & $0.63(14)$ & 0.58 & $F_{77}$ & $\beta(\mathrm{HBC})$ & $0.412(57)$ & 0.39 \\
\hline$F_{44}$ & $\mathrm{BC}$ & $2.85(30)$ & 2.76 & $F_{88}$ & $\gamma(\mathrm{BCO})$ & $0.502(69)$ & 0.52 \\
\hline$F_{12}$ & $\mathrm{BH}, \mathrm{CO}$ & $0.07(62)$ & 0.22 & $F_{56}$ & $\mathrm{BH}, \alpha$ & $-0.18(73)$ & 0.00 \\
\hline$F_{13}$ & $\mathrm{BH}, \alpha$ & $-0.34(54)$ & -0.26 & $F_{57}$ & $\mathrm{BH}, \beta$ & $0.2(18)$ & 0.00 \\
\hline$F_{14}$ & $\mathrm{BH}, \mathrm{BC}$ & $0.51(110)$ & 0.26 & $F_{58}$ & $\mathrm{BH}, \gamma$ & $0.0(11)$ & 0.03 \\
\hline$F_{23}$ & $\mathrm{CO}, \alpha$ & $-0.46(11)$ & -0.46 & $F_{67}$ & $\alpha, \beta$ & $0.07(19)$ & 0.11 \\
\hline$F_{24}$ & $\mathrm{CO}, \mathrm{BC}$ & $0.45(11)$ & 0.60 & $F_{68}$ & $\alpha, \gamma$ & $-0.05(22)$ & 0.02 \\
\hline$F_{34}$ & $\alpha, \mathrm{BC}$ & $-0.31(19)$ & -0.28 & $F_{78}$ & $\beta, \gamma$ & $-0.226(83)$ & -0.21 \\
\hline \multicolumn{8}{|c|}{ Compliants (Harmonic) } \\
\hline & & $c_{11}$ & $0.31(8)$ & $C_{55}$ & $0.30(10)$ & & \\
\hline & & $c_{22}$ & $0.0530(7)$ & $c_{66}$ & $2.93(59)$ & & \\
\hline & & $c_{33}$ & $1.76(9)$ & $c_{77}$ & $3.46(20)$ & & \\
\hline & & $c_{44}$ & $0.31(8)$ & $C_{88}$ & $2.68(35)$ & & \\
\hline & & $C_{12}$ & $0.003(3)$ & $C_{56}$ & $0.18(57)$ & & \\
\hline & & $C_{13}$ & $0.15(21)$ & $C_{57}$ & $-0.2(19)$ & & \\
\hline & & $c_{14}$ & $-0.04(10)$ & $c_{58}$ & $-0.1(14)$ & & \\
\hline & & $C_{23}$ & $0.04(1)$ & $C_{67}$ & $-0.5(22)$ & & \\
\hline & & $\mathrm{C}_{24}$ & $-0.005(2)$ & $C_{68}$ & $0.1(19)$ & & \\
\hline & & $C_{34}$ & $0.16(1)$ & $c_{78}$ & $1.51(39)$ & & \\
\hline
\end{tabular}
species are listed in Table IV.

\section{Normal coordinate calculations}

The first structure determination on $\mathrm{BH}_{3} \mathrm{CO}$ was by Bauer ${ }^{10}$ who confirmed that the molecule had $C_{3 v}$ symmetry and gave approximate values for molecular parameters. The most recent parameters are those determined from microwave studies by Venkatachar,

TABLE VI. Symmetry potential constants calculated for $\mathrm{BH}_{3} \mathrm{CO}$.

aThe units for force constants are mdyne $/ \AA$ for stretch, mdyne $\AA \cdot \mathrm{rad}^{-2}$ for bend and millidynes/ radian for stretch bend. For compliance constants the units are inverted.

btandard deviations in parentheses in units of last decimal place given. 


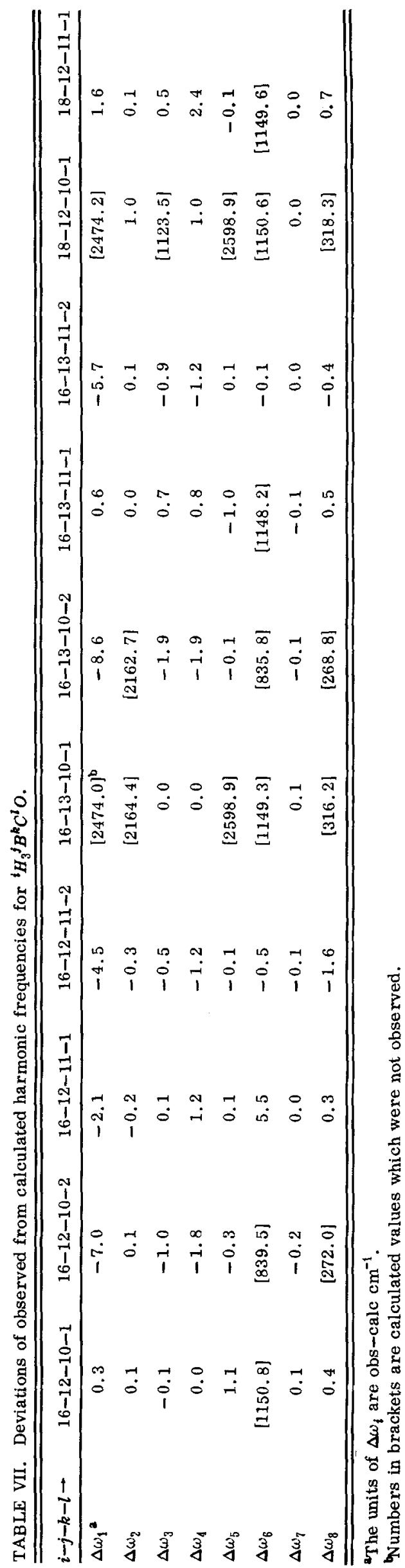

et al. ${ }^{11} ; r_{\mathrm{CO}}=1.135 \pm 0.01 \AA, R_{\mathrm{BC}}=1.534 \pm 0.01 \AA, d_{\mathrm{BH}}$ $=1.221 \pm 0.001 \AA, \angle \mathrm{HBC}=103.70 \pm 0.06^{\circ}$, and $\angle \mathrm{HBH}$ $=114.50 \pm 0.15^{\circ}$. Symmetry coordinates for this molecule were given previously by Taylor ${ }^{4}$ and later by McNaught ${ }^{12}$ who also gave explicit expressions for the symmetry $G$ matrix elements. Since other authors have not all used the same set, and also to clarify the numbering of the normal modes, we reproduce the symmetry coordinates used in Table $V$. The internal coordinates are defined in Fig. 3. Elements of the symmetry $G$ matrices were evaluated using the computer program of Schachtschneider ${ }^{13}$ and also from the expressions of McNaught ${ }^{12}$; agreement was found within normal roundoff error.

Force constants were determined using a standard iterative least squares procedure which fitted all isotopic frequencies in a given class simultaneously. The principal program used was that of Schachtschneider ${ }^{13}$ but parallel calculations were made using an independently written program at The University of Michigan with a laboratory designation of JACO-3D. Essentially identical results were obtained from the two programs, the refined values of the force constants agreeing well within the calculated dispersions of the constants with one or two exceptions. The exceptions were not considered serious and involved off-diagonal force constants which were not well determined, as judged by the magnitude of their dispersions. The discrepancies are attributed to small differences in convergence limits and the different method of damping used in the two programs. Weighting factors used in the refinement were proportional to $1 /(\Delta \nu)^{2} \lambda$ where $\Delta \nu$ is the estimated uncertainty in the observed frequency. The values of $1 /(\Delta \nu)^{2}$ are listed in Table IV. They do not include the uncertainties in anharmonicities, but do give a reasonable estimate of how well the isotope shifts are known which are the most important quantities in the least squares calculations. A zero weight was used for all frequencies where the experimental band was not observed with confidence (the values listed in the table in those cases have been estimated from isotope shifts). The exclusion of such frequencies left 32 frequencies in the $A_{1}$ class and 27 in the $E$ class actually used in the refinement of the 10 symmetry force constants in each class.

Inasmuch as previous force constant analyses utilized experimental (anharmonic) frequencies, the present calculations were extended to fit these as well. Because of uncertainties in some of the anharmonicity corrections, it turned out that the experimental frequencies could be fitted nearly as well as the harmonic, judged solely in terms of the average deviations of the calculated results. However, the primary force constants based on the harmonic values should be more meaningful than those calculated from the observed frequencies. With one exception $\left(F_{88}\right)$, the principal harmonic force constants ranged from $2 \%-15 \%$ higher than the anharmonic values. The interaction constants, of course, differed over a much larger range, particularly those which were not well determined.

Symmetry force constants determined from both the experimental and harmonic frequencies are listed in Table VI. Compliance constants obtained by inversion 
TABLE VII. Symmetry eigenvectors for fundamental modes of ${ }^{11} \mathrm{~B}^{1} \mathrm{H}_{3}{ }^{12} \mathrm{C}^{16} \mathrm{O}$.

\begin{tabular}{lcccc}
\hline \hline & \multicolumn{4}{c}{$A_{1}$} \\
$\nu, \mathrm{cm}^{-1}$ & $L_{\mathrm{BH}}$ & $L_{\mathrm{CO}}$ & \multicolumn{1}{c}{$L_{\alpha}$} & \multicolumn{1}{c}{$L_{\mathrm{BC}}$} \\
\hline 2471.5 & $0.99^{\alpha}$ & -0.02 & -0.21 & -0.03 \\
2214.9 & -0.05 & -0.38 & 0.11 & 0.25 \\
1112.5 & -0.13 & -0.04 & -1.13 & -0.12 \\
702.4 & 0.05 & -0.02 & 0.03 & -0.31 \\
& & & & \\
$\nu, \mathrm{cm}^{-1}$ & $L_{\mathrm{BH}}$ & $L_{\alpha}(\mathrm{HBH})$ & $L_{B}(\mathrm{HBC})$ & $L_{\gamma}(\mathrm{BCO})$ \\
\hline 2586.6 & 1.06 & 0.07 & -0.07 & 0.06 \\
1149.8 & 0.04 & 1.31 & 0.40 & -0.07 \\
843.8 & -0.06 & -0.54 & 0.73 & -0.36 \\
321.4 & -0.03 & -0.04 & 0.35 & 0.38 \\
\hline \hline
\end{tabular}

${ }^{2}$ Units for $L$ are such that $L L^{1}=G$.

of the $F$ matrices are included in the same table. As can be seen from Table VI, interaction constants involving the $\mathrm{B}-\mathrm{H}$ stretching coordinate uniformly were rather poorly determined both in the $A_{1}$ and $E$ classes. The deviations of calculated frequencies from those of Table IV are given in Table VII.

The potential energy distribution showed very little mixing of coordinates in the normal modes and consequently is not given here. A description of the normal modes can be gleaned from the eigenvectors listed in Table VIII for the normal species. The changes for isotopic species are not great.

\section{DISCUSSION}

The CO stretching force constant found here (19.24 mdyn/ $\AA$ ) appears to be slightly greater than that of free $\mathrm{CO}(19.02 \mathrm{mdyn} / \AA),{ }^{14}$ but less than that of $\mathrm{CO}^{+}(19.80$ mdyn/ $\AA$ ). ${ }^{14}$ A recent theoretical treatment ${ }^{15}$ of borane carbonyl indicates that "The $\mathrm{CO}$ bond of $\mathrm{BH}_{3} \mathrm{CO}$ is somewhat stronger than in free CO," in agreement with our findings. Also, their calculations ${ }^{15}$ indicate that there is electron transfer from the $\mathrm{MO}$ of $\mathrm{BH}_{3}$ to the antibonding $2 \pi \mathrm{MO}$ of $\mathrm{CO}$, the previously postulated ${ }^{2}$ hyper conjugative stabilization of the molecule which weakens the $\mathrm{CO}$ bond. Thus the $\mathrm{CO}$ bond tends toward that of $\mathrm{CO}^{+}$due to the $\mathrm{B}-\mathrm{C}$ sigma bonding but the donation of $\mathrm{BH}_{3}$ electrons to the $\mathrm{CO}$ antibonding $\pi$ orbital counter acts this effect, leaving a $\mathrm{CO}$ bond only slightly stronger than in free CO.

The theoretical calculations of Ermler et al. ${ }^{15}$ also indicate a B-C bond considerably weaker than a good single bond. We find a B-C force constant of 2.85 mdyn/ $\AA$ which is weaker than expected for the usual single bond (4-6 mdyn/ $\AA$ for $\mathrm{C}-\mathrm{C}, \mathrm{C}-\mathrm{N}$, etc. ), ${ }^{16}$ though it is somewhat stronger than the very weak $\mathrm{N}-\mathrm{F}$ bond in ONF $\left(F_{\mathrm{NF}}=2.2 \mathrm{mdyn} / \AA\right) .{ }^{17}$ The actual B-C force constant for a simple sigma bond may be even less than 2.85 mdyn/ $\AA$ since this includes the H...C hyperconjugative interaction if it exists. ${ }^{18}$

The interaction coordinate ${ }^{19}$ are of interest in discussing the bonding. For example, we find $(\mathrm{CO})_{\mathrm{BC}}$
$=-0.013$ and $(\alpha)_{\mathrm{BC}}=0.4$. Thus, when the $\mathrm{BC}$ bond is stretched a small amount for minimum energy the $\mathrm{CO}$ bond tends to contract by $1.3 \%$ of that amount. Thus, it appears to tend toward $\mathrm{CO}^{+}$rather than neutral $\mathrm{CO}$.

This suggest that near equilibrium the B-C bonding electrons tend to stay more with the boron atom than to move out with the $\mathrm{CO}$ group; or perhaps this is equivalent to an initial dissociative process toward $\mathrm{BH}_{3}^{-}+\mathrm{CO}^{+}$. At greater displacement of the $\mathrm{B}-\mathrm{C}$ bond, of course, the process must cross over into dissociation toward $\mathrm{BH}_{3}+\mathrm{CO}$.

The interaction of the $\mathrm{B}-\mathrm{C}$ stretch with the $\mathrm{HBH}$ angle, $\alpha$, expressed as $(\alpha)_{B C}$, indicates that a slight stretch of the B-C bond tends to open up the HBH angles for minimum energy. This could arise from two effects: the hyperconjugation tends to pull the hydrogens toward the carbon; the $\mathrm{BH}_{3}^{-}$group may have a larger $\mathrm{HBH}$ angle than found in $\mathrm{BH}_{3} \mathrm{CO}$.

The $\mathrm{BH}, \mathrm{BH}$ interaction is apparently very smallnegligible within one standard deviation. The work of Ermler, et al. ${ }^{15}$ suggests a strong $\mathrm{B}-\mathrm{H}$ bond, yet the force constant of $3.5 \mathrm{mdyn} / \AA$ is considerably less than for the $\mathrm{C}-\mathrm{H}$ bond of methane $(5.5 \mathrm{mdyn} / \AA)$.

One other interaction of interest is the $(\alpha)_{\text {co }}$ coordinate, $0.8 \mathrm{rad} / \AA$, which tells us that stretching the $\mathrm{CO}$ bond tends to open up the HBH angles for minimum energy. This is reasonable if one considers the hyper conjugation as analogous to back $\pi$ bonding in metal carbonyls; stretching the $\mathrm{CO}$ bond lowers the energy of its antibonding $\pi$ orbitals making them more available for accepting the $\mathrm{BH}$ electrons. Most of the other interactions calculated are too poorly determined to be meaningful.

In general, the experimental results are consistent with the most recent theoretical results ${ }^{15}$ though the correlations cannot be considered unique.

${ }^{1}$ R. L. DeKock, A. C. Sarapu, and R. F. Fenske, Inorg. Chem. 10, 38 (1971).

${ }^{2}$ A. B. Burg, Rec. Chem. Prog. 15, 159 (1954); W. A. G. Graham and F. G. A. Stone, J. Inorg. Nucl. Chem. 3, 164 (1956).

${ }^{3}$ G. W. Bethke and M. K. Wilson, J. Chem. Phys. 26, 1118 (1957).

${ }^{4}$ R. C. Taylor, J. Chem. Phys, 26, 1131 (1957); 27, 979 (1957).

${ }^{5}$ S. Sundaram and F. F. Cleveland, J. Chem. Phys, 32, 166 (1960).

6I. Shapiro, H. G. Weiss, M. Schmich, S. Skolinck, and G. B. L. Smith, J. Am. Chem. Soc. 74, 901 (1952).

${ }^{7} \mathrm{~J}$. C. Carter, Ph. D. thesis, (University of Michigan, Ann Arbor, Michigan, 1960).

${ }^{8} \mathrm{G}$. Herzberg, Infrared and Raman Spectra of Polyatomic Molecules (Van Nostrand-Reinhold, New York, 1945), p. 216.

${ }^{9}$ (a) C. Pepin, L. Lambert, and A. Cabana, J. Mol. Spectrosc. 53, 120 (1974); (b) L. Lambert, C. Pepin, and A. Cabana, J. Mol. Spectrosc. 44, 578 (1972).

${ }^{10} \mathrm{~S}, \mathrm{H}$. Bauer, J. Am. Chem. Soc. 59, 1804 (1937).

${ }^{11}$ A. C. Venkatachar, R. C. Taylor, and R. L. Kuczkowski, J. Mol. Struct. 38, 17 (1977).

${ }^{12}$ I. J. McNaught, J. Mol. Spectrose. 39, 163 (1971).

${ }^{13} \mathrm{~J}$. H. Schachtschneider, "Vibrational Analysis of Polyatomic Molecules," Technical Report, Shell Development Co., Emeryville, California, (a) SD-9064-I; (b) SD-9032-VII. 
${ }^{14} \mathrm{~L}$. H. Jones, Inorganic Vibrational Spectroscopy, (Marcel Dekker, New York, 1971), pp. 48, 185.

${ }^{15}$ W. C. Ermler, F. D. Glasser, and C. W. Kern, J. Am. Chem. Soc. 98, 3799 (1976).

${ }^{16}$ E. B. Wilson, J. C. Decius, and P. C. Cross, Molecular Vibrations, (McGraw-Hill, New York, 1955), p. 175.
${ }^{17}$ L. H. Jones, L. B. Asprey, and R. R. Ryan, J. Chem. Phys. 47, 3371 (1967).

${ }^{18}$ Actually, we do not know what the force constant for a good $\mathrm{B}-\mathrm{C}$ single bond should be; it may, in fact, be less than that for $\mathrm{C}-\mathrm{C}, \mathrm{C}-\mathrm{N}$, etc.

${ }^{19}$ Ref. 14, pp. 29-30. 